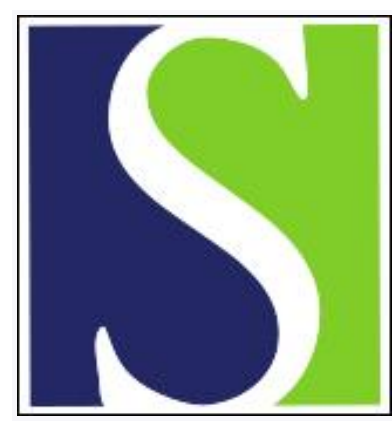

Scand J Work Environ Health 2004;30(3):253

https://doi.org/10.5271/sjweh.787

Issue date: Jun 2004

\title{
Neuropathy in grout workers
}

by Cornblath DR

Affiliation: Meyer 6-181a, Johns Hopkins Hospital, Baltimore MD 21287-7681, USA. dcornbl@jhmi.edu

Refers to the following text of the Journal: 2004;30(1):21-29

The following article refers to this text: 2004;30(3):253-254

Key terms: grout worker; letter to the editor; neuropathy

This article in PubMed: www.ncbi.nlm.nih.gov/pubmed/15250655 


\section{Letters to the Editor}

Scand J Work Environ Health 2004;30(3):253

\section{Neuropathy in grout workers}

This letter concerns the recent paper by Kjuus and his co-workers (1). In this paper, the exposed tunnel workers were compared with 50 other tunnel workers not using grout. The main finding was the surprising one that the nerve conduction abnormalities in the exposed tunnel workers were reduced sensory action potential of the conduction velocity and prolonged motor distal latency in the ulnar nerve. While the authors suggested that this finding represented neuropathy, I believe there is a more likely explanation. The nerve conduction findings are typical of ulnar neuropathy in the wrist $(2,3)$ most commonly from external compression such as the use of handtools, bicycle riding, video games, and the like. This possibility would fit nicely with the improvement over 12 months, the focal nature of the nerve conduction abnormalities, and the discordance of these findings from those of a generalized, distal, dying-back toxic neuropathy. I suggest that the authors reinterview the workers and find out what they did with their hands during the grout work and compare that activity with that of the nongrout tunnel workers.

\section{References}

1. Kjuus H, Goffeng LO, Heier MS, Sjöholm H, Øvrebø S, Skaug V, Paulsson B, Törnqvist M, Brudal S. Effects on the peripheral nervous system of tunnel workers exposed to acrylamide and $\mathrm{N}$-methylolacrylamide. Scand J Work Environ Health 2004;30(1):21-29.

2. Hunt JR. The thenar and hypothenar types of neural atrophy of the hand. Am J Med Sci 1911;141:224-41.

3. Stewart JD. Focal peripheral neuropathies. 2nd ed. New York (NY): Raven Press; 1993.

David R. Cornblath, $M D$

Meyer 6-181a

Johns Hopkins Hospital

Baltimore MD 21287-7681

USA

[E-mail:dcornbl@jhmi.edu]

\section{Authors' reply to "Neuropathy in grout workers"}

In a recent paper (1), we related a slight, mostly reversible reduction in nerve conduction velocities (NCV) in the arms of tunnel workers to exposure to acrylamide and N-methylolacrylamide. We would like to thank Dr Cornblath for his suggestion of another possible mechanism, that of ulnar neuropathy from external compression due to the use of handtools and the like. On an individual basis, we obviously cannot exclude that some of the reduced NCV findings could be related to mechanical exposure factors such as the use of handtools and not to acrylamide exposure. On a group basis, however, we do not think this is a likely explanation, for the following reasons. First, the optimal reference group in epidemiology is comparable to the index group, except for the actual exposure under study. Our choice of other tunnel workers, doing the same type of work, but not exposed to acrylamide grout as referents, would fulfill these requirements. In detailed interviews with the participants, the reference group reported the same number of years in construction work as the index group (20.4 years versus 19.3 years), almost all had used vibrating handtools (91.9\% versus $100 \%)$, and for the same length of time ( 7.9 years versus 6.0 years). This information gives no support to potential incomparability between the two groups in relation to the use of handtools. Furthermore, after 12 months of follow-up, when both groups were still working as construction workers (and still exposed to vibrating handtools), we found significant improvement in the NCV of the exposed group, which, for both the median and the ulnar nerves, was related to qualitative indicators of acrylamide exposure ("tunnel time" and "exposure time index"). In these intraindividual comparisons, we believe that betweengroup confounding (eg, from the use of handtools) should be avoided.

In general, tunnel workers are exposed to a variety of exposure factors, which could, in part, confound the observed effects. Although we did not obtain a complete

Scand J Work Environ Health 2004, vol 30, no 3 
comparability between the two groups in all aspects (see table 1 of the original article), we still believe that the chosen design secured valid inter- and intraperson comparability between the groups, and, in particular, in relation to the aspect of mechanical compression as an alternative explanation of our results.

\section{References}

1. Kjuus H, Goffeng LO, Heier MS, Sjöholm H, Øvrebø S, Skaug V, Törnqvist M, Brudal S. Effects on the peripheral nervous system in tunnel workers exposed to acrylamide and
N-methylol acrylamide. Scand J Work Environ Health 2004;30(1):21-29.

Helge Kjuus', Lars Ole Goffeng, Mona Skard Heier, Hans Sjöholm, Steinar Øvrebø, Vidar Skaug, Birgit Paulsson, Margareta Törnqvist, Stein Brudal

$1 \quad$ Address for correspondence:

Dr Helge Kjuus

Department of Occupational Medicine,

National Institute of Occupational Health

Pb 8149 Dep

N-0033 Oslo, Norway

[E-mail:Helge.Kjuus@stami.no] 